\title{
¿Información Geográfica Voluntaria (IGV) para monitorear recursos forestales en México?
}

\author{
Jean François Mas Caussel*
}

Recibido el 13 de junio de 2016; aceptado el 18 de julio de 2016

Debido al uso cada vez masivo de aparatos como tablets o teléfonos celulares equipados de un GPS, se incrementó de forma exponencial la cantidad de información georreferenciada producida por los usuarios, que puede ser recopilada y difundida a través de Internet. Existen muchas aplicaciones que explotan esta posibilidad de obtener información de cientos o miles de usuarios. Por ejemplo, la aplicación Waze permite al conductor de un automóvil equipado de un smartphone saber en tiempo real la ruta óptima para llegar a su destino, evitando embotellamientos, al mismo tiempo que su propia velocidad es registrada y alimenta el sistema para calcular la velocidad en la ruta que está siguiendo. Otros ejemplos de uso de IGV conciernen la prevención y gestión de desastres. Por ejemplo, después el terremoto de abril pasado en Ecuador, las plataformas Ushahidi y Open Street map permitieron recopilar y categorizar avisos emitidos por los usuarios con su descripción y localización geográfica así como actualizar los mapas de las zonas más afectadas para facilitar la llegada de ayuda

La mayoría de los ejemplos provienen de ambientes urbanos. ¿Estas técnicas de creación y recopilación de información son factibles en ambientes rurales de países como México? Existe una brecha digital entre el mundo rural y el urbano. De acuerdo con un estudio realizado por Telecomunicaciones de México, 20 millones de personas viven en localidades rurales sin cobertura de telefonía celular. De la misma forma sólo $57.4 \%$ de la población mayor a seis años son usuarios de servicios de Internet. La ubicación geográfica y la baja densidad de población en diversas regiones del país, hacen que sea poco atractivo para la iniciativa privada establecer estos servicios de telecomunicación. Las áreas con más recursos bióticos coinciden con las de menor acceso a estas tecnologías, por lo cual la falta de acceso podría ser un obstáculo a la obtención de IGV para estudios sobre bosques, biodi-

* Centro de Investigaciones en Geografía Ambiental, Universidad Nacional Autónoma de México, correo electrónico: jfmas@ciga.unam.mx 
versidad, etcétera. Sin embargo, esta brecha se está reduciendo año con año y una vez que la cobertura telefónica es establecida, la adopción de las tecnologías es muy rápida.

Otros preguntas ampliamente debatidos entorno a la IGV conciernen la motivación para participar en este tipo de iniciativa en regiones donde la población tiene muchos problemas para subsistir y donde existe a veces desconfianza hacía el gobierno e iniciativas externas. Finalmente, otra pregunta ya muy discutida, es la calidad de los datos generado por voluntarios. Respecto a este último aspecto, existen métodos de análisis de la información que permite evaluar su calidad.

Existen algunos ejemplos exitosos en ambientes rurales de otros países que son muy alentadores. Por ejemplo, un sistema de monitoreo de los bosques en tiempo casi real basado en IGV que fue implementado en la reserva de la biosfera de Kafa en Etiopía. El sistema permite adquirir de forma continua datos de percepción remota y de un monitoreo comunitario realizado a través el uso de dispositivos móviles, presentar en la web y en redes sociales en tiempo casi real perturbaciones en los bosques detectadas con base en el análisis de las imágenes de satélite y hacer interactuar las alertas de perturbación forestal y la comunidad de usuarios para mejorar la recopilación de datos en campo. Los datos obtenidos por los expertos locales incluyen la tipificación de los cambios, su localización geográfica y fotografías georreferenciadas.

Si bien el uso de IGV no es simple, es sin duda una forma poderosa de obtener una gran cantidad de información que complementa las fuentes más convencionales de recopilación de información (imágenes, campañas de recopilación de datos en campo). 